\title{
Evaluación del paciente con dispepsia: cuestionamientos a la luz del descubrimiento del Helicobacter pylori
}

\begin{abstract}
Paciente 1
Un paciente de 32 años consulta por dolor epigástrico, que a veces calma con las comidas, y acidez. Fuma 10 cigarrillos por día y no tiene otros antecedentes de importancia. Los síntomas comenzaron hace 2 meses cuando estaba pasando por un momento difícil en el trabajo y había nacido su primer hija. Varios años atrás tuvo un cuadro similar y le habían indicado antiácidos por lo que ahora volvió a tomarlos aunque con poco resultado. Un amigo le recomendó tomar 2 semanas de ranitidina y a los pocos días estaba casi asintomático. Decidió consultar porque los síntomas aparecieron nuevamente al dejar la medicación. Las cosas en el trabajo están mucho mejor pero los síntomas están igual que al principio y le preocupa tener algo mas grave que una simple acidez.
\end{abstract}

\section{Paciente 2}

Paciente varón de 54 años que consulta por sensación de distensión postprandial y dolor epigástrico esporádico. Los síntomas comenzaron hace mas de un mes y se fueron agravando en el último tiempo. El paciente no tiene antecedentes de importancia y es la primera vez que tiene sintomas gastrointestinales de este tipo. Viene a la consulta acompañado por su esposa y su hijo que están preocupados y creen que hasta incluso puede haber bajado un poco de peso.

\section{Paciente 3}

Paciente mujer de 28 años. Vive con su madre, con la que tiene una relación difícil. En los últimos años realizó múltiples consultas por diferentes motivos: anticoncepción, cervicalgias, cuadros de vía aérea superior, constipación, mareos, astenia, cefaleas, etc. Viene a la consulta a realizar el examen ginecológico de rutina pero además quiere consultar por que hace una semana comenzó con distensión ("me hincho") y acidez. Este nuevo síntoma le molesta y le preocupa. Le gustaría tomar algo que le alivie y además quiere saber si no sería conveniente hacer una ecografía o algún estudio para estar seguros que no es nada grave.

\section{Evaluación de los pacientes con dispepsia}

¿Que tienen en común estos pacientes? Bueno, todos tienen dispepsia ya que podemos definir como dispepsia a cualquier síntoma atribuible a disfunción del tracto gastrointestinal superior : dolor epigástrico, pirosis (acidez), intolerancia a las comidas, eructos, distensión abdominal, náuseas y vómitos. Sin embargo estos tres pacientes son muy diferentes entre sí, y será diferente la forma en que deberán ser abordados.

Desde siempre la evaluación del paciente con dispepsia constituyó un desafio para el médico. Por un lado la amplia gama de patologías que pueden estar presentes en un paciente que consulta por dispepsia: úlcera gástrica o duodenal, reflujo gastroesofágico, ninguna anormalidad, cáncer gástrico, etc. En realidad, si estudiásemos a todos los pacientes con dispepsia y ordenásemos los diagnósticos por orden de frecuencia encontraríamos: Dispepsia no ulcerosa (esto significa ninguna anormalidad orgánica demostrable) en un 40 a $65 \%$, úlcera gastroduodenal (UGD) 5 a $15 \%$, reflujo gastroesofágico 5 a $10 \%$, colon irritable 5 a $10 \%$, litiasis vesicular $5 \%$ y cáncer gástrico < $1 \%$.

La otra dificultad radica en que los datos del interrogatorio y del examen físico ayudan poco para definir el diagnóstico en la mayoría de los casos. Es decir que el paciente con distensión y dolor epigástrico que calma con las comidas puede no tener ninguna anormalidad y la úlcera péptica puede estar presente en el paciente que simplemente tiene acidez. Es más, la úlcera puede estar presente incluso en pacientes asintomáticos. Entonces, ¿¿como saber a que pacientes estudiar?

Debido a que muchos de los pacientes que consultan por dispepsia tienen trastornos autolimitados, y que no tendría sentido estudiar inmediatamente a todos ellos, siempre se buscó una forma de normatizar su manejo. La más extendida es la norma del American College of Physicians que recomienda tratar empiricamente los síntomas de dispepsia y estudiar sólo a los pacientes en los que falla este tratamiento empírico inicial. Es decir: si un paciente consulta por dispepsia debemos darle un tratamiento empírico durante 8 se-manas, si los síntomas no mejoran o empeoran al terminar el tratamiento debemos considerar estudiarlo con fibro-endoscopía digestiva alta (FEDA). El tratamiento se elige en base a la sintomatología del paciente, pueden ser antiácidos, ranitidina o procinéticos como metoclopramida, domperidona o cisapride. Por supuesto que esta alternativa no es válida en aquellos pacientes con evidencia clara de enfermedad orgánica como anemia, pérdida de peso, disfagia, dolor biliar, masa abdominal, vómitos o hematemesis, melena u otros pacientes que por ser considerados de mayor riesgo (comienzo de los síntomas luego de los 40-50 años, uso de AINEs, antecedentes de úlcera, etc.) deben ser estudiados inmediatamente (ver algoritmo).

El tratamiento empírico tiene dos objetivos principales: 1) aliviar los síntomas, aunque sea a través del efecto placebo; 2) evitar los estudios innecesarios (la FEDA) en aquellos pacientes con síntomas autolimitados para prevenir las cascadas diagnósticas innecesarias. Con este esquema de selección evitamos tener que estudiar a muchos pacientes con cuadros leves y autolimitados en los cuales el tratamiento empírico logrará "curar" la sintomatología y seleccionamos a aquellos pacientes en los cuales la probabilidad de enfermedad orgánica (UGD o cáncer) es más alta. Por supuesto, la falla terapéutica en pacientes de bajo riesgo (40-50\% de los casos) no significa que debamos necesariamente realizar una FEDA.

Esta norma, muy extendida y utilizada desde hace años por médicos en todo el mundo, es ahora cuestionada a la luz del descubrimiento de la relación entre el Helicobacter pylori (H. pylori) y la UGD y en consecuencia se han propuesto diferentes modificaciones.

\section{El Helicobacter pylori y las afecciones gastroduodenales}

Ya en 1975 se había descripto la presencia de bacterias espiraladas en relación con la gastritis pero no habían podido ser cultivadas. En 1982, debido a un fin de semana largo, unas placas de cultivo fueron accidentalmente dejadas en la estufa de incubación más tiempo del previsto y se obtuvo el primer cultivo de "Campylobacter pyloridis". La asociación de esta bacteria con la UGD fue confirmada en 1985 y en 1989 fue rebautizada como Helicobacter pylori.

La infección por H. Pylori es adquirida en la infancia. Se calcula que hasta un 50\% de la población mundial está infectada. La mayoría de los infectados cursa en forma asintomática. La prevalencia de la infección puede llegar hasta el $90 \%$ en algunos países en vías de desarrollo y se correlaciona de manera inversamente proporcional al nivel socioeconómico.

La infección habitualmente permanece en el estómago por décadas, pudiendo llevar a la atrofia y a la metaplasia siendo la principal causa de gastritis crónica. En unos pocos pacientes la infección por 
H. pylori llevará a la aparición de UGD. También está visto que esta metaplasia puede llevar en algunos casos a la displasia y al carcinoma gástrico.

En la actualidad, el $\mathbf{H}$. pylori es la principal causa reconocida de UGD $(90 \%)$. En el resto de los casos (10\%) casi siempre es posible demostrar el uso de AINES como causa de la úlcera. Otras causas, como el síndrome de Zollinger-Ellison, enfermedad de Crohn, herpes, etc., ocupan un lugar marginal.

Hoy en día está ampliamente aceptado que en todo paciente al que se le efectúa una FEDA y se le encuentra una úlcera gástrica o duodenal se le debe tomar una muestra para confirmar la presencia de $\mathrm{H}$. pylori. Si se confirma su presencia en pacientes con úlcera se debe dar tratamiento antibiótico específico para la erradicación del germen. ¿Por que? Porque la erradicación del H. pylori colabora en la curación de la úlcera pero sobre todo provoca una dramática reducción de las recidivas.

En los pacientes con H. Pylori y úlcera se recomiendan tratamientos con dos o más antibióticos debido a la alta resistencia del germen a monodrogas. Estos son algunos ejemplos de esquemas con un $90 \%$ más de erradicación: 1) Ranitidina 150 mg 2 por día por 6 semanas; subsalicilato de bismuto 2 tabletas 4 veces/día; metronidazol 200 $\mathrm{mg} 4$ veces/día; tetraciclina $500 \mathrm{mg} 4$ veces/día (esta se puede reemplazar por $1 \mathrm{~g}$ de amoxicilina c/12 hs). Los últimos tres productos deben tomarse por dos semanas. 2) 0meprazol $20 \mathrm{mg} /$ día por 10 días; bismuto igual dosis que la anterior; metronidazol $500 \mathrm{mg} 3$ veces/día y tetraciclina $500 \mathrm{mg} 4$ veces/día. En este esquema los últimos tres productos deben tomarse sólo por una semana. 3) Omeprazol $20 \mathrm{mg}$; amoxicilina $1 \mathrm{~g} \mathrm{c} / 12 \mathrm{hs}$; y claritromicina $500 \mathrm{mg}$ dos veces/día. Todos los productos de este esquema se deben tomar durante 7 a 10 días.

La incorporación del tratamiento del H. pylori ha permitido modificar el curso de la UGD. Tanto la úlcera duodenal como la gástrica tenían tasas de recidiva del 60 al $80 \%$ dentro del primer año luego del tratamiento (muchas veces asintomáticas). En los pacientes en quienes se ha erradicado el $\mathrm{H}$. pylori, la recurrencia ulcerosa es un hecho excepcional ( $10 \%$ ).

\section{Así como es clara la relación entre úlcera y H. pylori, hasta el} momento no se ha podido demostrar una relación entre $\mathrm{H}$. pylori y dispepsia. Tampoco se ha podido demostrar que la erradicación del germen alivie los síntomas de los pacientes con dispepsia que no son portadores de úlcera. Por lo tanto, en los pacientes en que se realiza una FEDA y no se encuentra UGD, no está indicado buscar $\mathrm{H}$. pylori ya que, aunque se demuestre la presencia del germen, no está indicado tratarlo pese a que el paciente esté sintomático.

\section{Cambios posibles en el manejo del paciente con dispepsia}

Recordemos nuevamente la norma que es utilizada actualmente: a los pacientes con dispepsia indicarles un tratamiento empírico y estudiar solo en aquellos casos en que falla este tratamiento empírico inicial.

El descubrimiento de la relación entre el H. Pylori y la úlcera y la disponibilidad de tests no invasivos para el diagnóstico de infección han hecho surgir cuestionamientos al esquema de manejo de la dispepsia propuesto por el American College of Physicians.

La serología comienza a estar disponible como estudio de laboratorio a un costo similar a otros estudios de serología como puede ser el de la rubeola. Es $95 \%$ sensible y específica, mide presencia de IgG y se interpreta como positiva o negativa. Es muy útil para el diagnóstico de infección aunque por el momento, debido a la lentitud con que desaparecen los anticuerpos, no es un método de elección para confirmar la erradicación del germen.

En este nuevo escenario, ¿Cuál es el principal problema de la norma del American College of Physicians? Es evidente que el tratamiento empírico de la dispepsia nos hace perder la posibilidad de erradicar el H. pylori en los pacientes con UGD portadores del germen. Supongamos un paciente joven, sin factores de riesgo importantes, que nos consulta por dispepsia y nosotros decidimos darle tratamiento empírico durante 2 meses con anti-H2. Pocos años atrás, podíamos asumir que, aún en el caso de que ese paciente hubiese tenido una UGD que quedó sin diagnóstico por no haber solicitado una FEDA, de cualquier manera estaba recibiendo el tratamiento adecuado. Aunque le hubiésemos hecho la FEDA y diagnosticado la UGD, el tratamiento hubiese sido prácticamente el mismo: 2 meses de tratamiento con anti-H2. Hoy en día no podemos afirmar lo mismo ya que sabemos que los pacientes con diagnóstico de UGD deben recibir un tratamiento específico para la erradicación del H. Pylori cuando éste se halla presente.

Un ejemplo puede ser el paciente 1. Podemos pensar que debido a la evolución de los síntomas hay cierta posibilidad de que sea portador de una UGD. ¿Es imprescindible realizar una FEDA? Podemos decir que no. Tomó ranitidina en forma irregular a pesar que le aliviaba los síntomas. Podemos indicarle un tratamiento continuo por 8 semanas. En el peor de los casos, si el paciente es portador de una UGD, ésta seguramente se curará con 8 semanas de tratamiento. Sin embargo, hoy tenemos la posibilidad de hacer algo mas. Si el paciente tenía una úlcera y era portador de $\mathrm{H}$. pylori, con esta conducta nos quedamos sin la chance de erradicar el germen y aumentar la tasa de curación, pero sobre todo prevenirle las recidivas de la UGD en los próximos años.

El tratamiento empírico puede curar la UGD si ésta se halla presente pero deja a muchos pacientes portadores de H. Pylori sin el tratamiento específico.

Por esto, en los últimos años los médicos han sido más "generosos" en la indicación de la FEDA ya que en la actualidad es posible ofrecerles a los pacientes con UGD un tratamiento más integral al erradicar el H. Pylori y reducir las posibilidades de recidivas futuras. Otro problema del tratamiento empírico es que el costo de la medicación sintomática es alto, sobre todo en aquellos pacientes que continúan tomándola por años y que muchos de estos pacientes continúan realizando múltiples consultas por el mismo síntoma.

El costo del tratamiento sintomático y las consultas de los pacientes que no fueron estudiados se ha convertido en una preocupación. Además, el número de endoscopías se ha incrementado enormemente, la mayor parte de ellas realizadas en pacientes sin patología. Esto deteriora la calidad de atención y aumenta los costos. Pero el elemento más importante es: ¿para qué se realiza una FEDA? El principal objetivo, sobre todo en los pacientes menores de 45 años donde la prevalencia del cáncer gástrico es muy baja, es detectar a los pacientes que tienen UGD. Ahora bien, ¿̇cuál es la probabilidad de que un paciente con dispepsia que no tomó AINES en forma significativa tenga una UGD si no está infectado por $\mathrm{H}$. pylori? prácticamente nula.

Entonces, ¿por qué no hacer un test no invasivo para $\mathrm{H}$. pylori, como la serología, antes de hacer la FEDA? De acuerdo al test, realizaríamos la FEDA sólo a aquellos pacientes que demostraron ser portadores de $H$. pylori ya que sabemos que entre los pacientes con dispepsia que son seropositivos la prevalencia de UGD es mucho más alta (15-35\%) y podríamos evitar hacer la endoscopía en los pacientes que no son portadores de H. pylori.

De esta manera algunos autores han hecho la siguiente recomendación: estudiar con FEDA sólo a aquellos pacientes con dispepsia en los que un test no invasivo para H. pylori (serología) ha dado positivo.

Al hacer la FEDA, si se encuentra una UGD se debe indicar un tratamiento que incluya la erradicación del H. pylori y si no hay UGD se debe tranquilizar al paciente en cuanto a que no tiene una patología grave (tiene dispepsia no ulcerosa) y si es necesario se debe indicar medicación sintomática. Seguir esta recomendación, que evita hacer endoscopías en los pacientes seronegativos, puede llegar a reducir un 30 a $50 \%$ la necesidad de endoscopias sin perderse de diagnosticar UGD. Esta recomendación, al reducir el número de FEDAs, podría perder ciertos diagnósticos aunque es probable que esto no sea significativo. 
Supongamos que hemos decidido adoptar la norma anterior. Todavía podríamos preguntarnos: ¿Para qué solicitamos una FEDA en los pacientes con dispepsia una vez que la serología dio positiva para $\mathrm{H}$. pylori? La respuesta es: para confirmar la presencia de UGD ya que sólo si hay UGD se debe indicar un tratamiento que incluya antibióticos.

Con este esquema nos habremos ahorrado una importante cantidad de endoscopías. Sin embargo, todavía estaremos realizando muchas endoscopías inútilmente porque la mayor parte de los paciente con dispepsia, aún cuando sean portadores de $\mathrm{H}$. pylori, tienen endoscopias normales. Entonces, ¿ Por qué, en vez de someter a todos estos pacientes a una FEDA, no les damos directamente tratamiento para H. pylori? Si bien es cierto que estaremos tratando a muchos pacientes que no tienen UGD, en todos ellos, la serología para $\mathrm{H}$. pylori ha dado positiva.

Otra posibilidad sería entonces recomendar: a los pacientes con dispepsia se los podría estudiar inicialmente con un método no invasivo para H. pylori (serología). Si éste da positivo, dar un tratamiento antibiótico para erradicar el germen sin necesidad de realizar FEDA. Si da negativo, reasegurar al paciente y manejarlo con medicación sintomática.

Estudios de costo efectividad basados en valores de los EE.UU. le han dado la razón a esta última alternativa demostrando que es más efectivo tratar directamente para $\mathrm{H}$. pylori a todos los pacientes con dispepsia que son portadores antes que hacerles una FEDA. De esta manera se evita tener que realizar una FEDA a un gran número de pacientes.

Por supuesto que en ambas alternativas, en los pacientes de mayor riesgo (síntomas de enfermedad orgánica, edad mayor de 45 años, uso de AINES, anemia), la decisión de estudiarlos debe ser independiente de la serología para $\mathrm{H}$. pylori.

La norma del American College of Physicians sigue siendo válida para un gran número de pacientes, sobre todo hasta que la serología para $H$. pylori se encuentre ampliamente disponible. Sin embargo, estos nuevos estudios permiten vislumbrar que en el futuro la evaluación de los pacientes con dispepsia será diferente a como había sido hasta el momento.

Para resumir, volvamos nuevamente a los pacientes presentados al inicio. En el caso del paciente 1 se nos abren varias posibilidades. Siguiendo el manejo clásico podemos adoptar dos conductas: la primera es asumir que el paciente no cumplió adecuadamente el tratamiento, indicarle 8 semanas de ranitidina y decidir según la evolución. Si los síntomas no mejoran, o recurren una vez finalizado el tratamiento, solicitar la FEDA. La otra posibilidad es considerarlo como una fa!la del tratamiento y solicitarle una FEDA en ese momento porque evaluamos que las posibilidades de úlcera son ahora más altas.
Si tenemos disponible la serología para $\mathrm{H}$. pylori podemos plantearnos otras alternativas. Puede ser que el paciente no desee hacerse una FEDA, o que la FEDA no esté disponible en el lugar en el que trabajamos, o simplemente puede parecernos preferible manejar a este paciente de una forma más conservadora. Podemos solicitar una serología y si ésta es negativa no solicitar FEDA y manejarlo con medicación sintomática. Si la serología es positiva podríamos solicitar la FEDA o indicarle directamente un tratamiento para erradicar el germen.

En el caso del paciente 2 la situación es más clara. Debido a la edad del inicio de los sintomas, un estudio inicial con FEDA seguramente será la conducta más correcta. En este caso es preferible no dar un tratamiento empírico, ya que las chances de enfermedad orgánica son más altas. Tampoco sería correcto solicitar serología, ya que una serología negativa podrá descartar úlcera si el paciente no tomó AINEs; pero no puede descartar la presencia de cáncer gástrico. La paciente 3 parece ser el caso ideal para un manejo tradicional. La posibilidad de que los síntomas se deban a un cuadro autolimitado son muy altas. Un tratamiento sintomático inicial nos permitirá tomarnos el tiempo necesario para evaluar la evolución del cuadro. Solo en el caso que los síntomas empeoren o continúen en el tiempo pensaremos en profundizar más los estudios. Llegado el caso tanto la FEDA como la serolgía serán alternativas válidas.

Hay todavía algunas consideraciones que deben ser hechas acerca de estas nuevas alternativas. Hasta el momento no hay evidencia que logre demostrar que los pacientes con dispepsia que no tienen UGD se beneficien al erradicar el $\mathrm{H}$. pylori. Debido a esto, muchos pacientes recibirán un tratamiento antibiótico sin un beneficio comprobado. También existe cierta preocupación de que el tratamiento antibiótico indiscriminado lleve a un aumento de la resistencia bacteriana. Por otro lado, una FEDA negativa da un importante reaseguro de que el paciente no tiene una enfermedad significativa. No queda claro hasta qué punto una serología negativa o un tratamiento empírico pueden dar la misma seguridad al paciente. Con respecto a la costoefectividad de estas alternativas, hay que tener en cuenta que fue medida en EE.UU., donde el costo de la FEDA es muy alto y muy bajo el de la serología y por lo tanto no es directamente extrapolable a nuestro país.

A pesar que la mayor parte de las investigaciones acerca del $\mathrm{H}$. pylori y su relación con las afecciones gastroduodenales son muy recientes, ya es posible ver que se han producido grandes cambios. Si bien es difícil que estos pacientes vuelvan a ser manejados y tratados como lo eran 15 años atrás, todavía debemos esperar a que varios aspectos de la relación del $\mathrm{H}$. pylori con el hombre se aclaren para poder definir con certeza las conductas a seguir. La convivencia del hombre con el H. pylori lleva siglos y aún no conocemos en su totalidad los efectos a largo plazo de su erradicación. Entre aquellos que sostienen que "el único Helicobacter bueno es el Helicobacter muerto" y los que se niegan a admitir su existencia se encuentra hoy la posición equilibrada del médico frente a su paciente.

\section{Dr. Andrés Pichon Rivière}

Sistema de Protección Médica

\section{Referencias:}

Briggs AH, et al. Cost effectiveness of screening for and eradication of Helicobacter pylori in management of dyspeptic patient under 45 years of age. BMJ 1996; 312 (7042): 1321-5. Bytzer P, et al. Empirical H2-blocker therapy or prompt endoscopy in management of dyspepsia. Lancet 1994; 343(8901): 811-6.

Goodwin CS, et al. Helicobacter pylori infection. Lancet 1997; 349(9047): 265-9.

Hentschel E, et al. Effect of ranitidine and amoxicillin plus metronidazole on the eradication of Helicobacter pylori and the recurrence of duodenal ulcer. N Eng J Med 1993; 328(5): 308-12.

Hopkins RJ, et al. Helicobacter pylori: the missing link in perspective. Am J Med 1994; 97(3): 265-77.

Marshall BJ. The 1995 Albert Lasker Medical Research Award. Helicobacter pylori. The etiologic agent of peptic ulcer. JAMA 1995; 274(13): 1064-6.

Moayyedi P, et al. Validation of a rapid whole blood test for diagnosing Helicobacter pylori infection. BMJ 1997; $314(7074): 119$.

Ofman JJ, et al. Management strategies for Helicobacter pylori-seropositive patients with dyspepsia: clinical and economic consequences. Ann Intern Med 1997 ; 126 (4): $280-91$.

Parsonnet J, et al. Modelling cost-effectiveness of Helicobacter pylori screening to prevent gastric cancer: a mandate for clinical trials. Lancet 1996; 348(9021): 150-4.

Patel P, et al. Prospective screening of dyspeptic patients by Helicobacter pylori serology. Lancet 1995; 346(8986): 1315-8. 


\section{Dispepsia: Algoritmo}

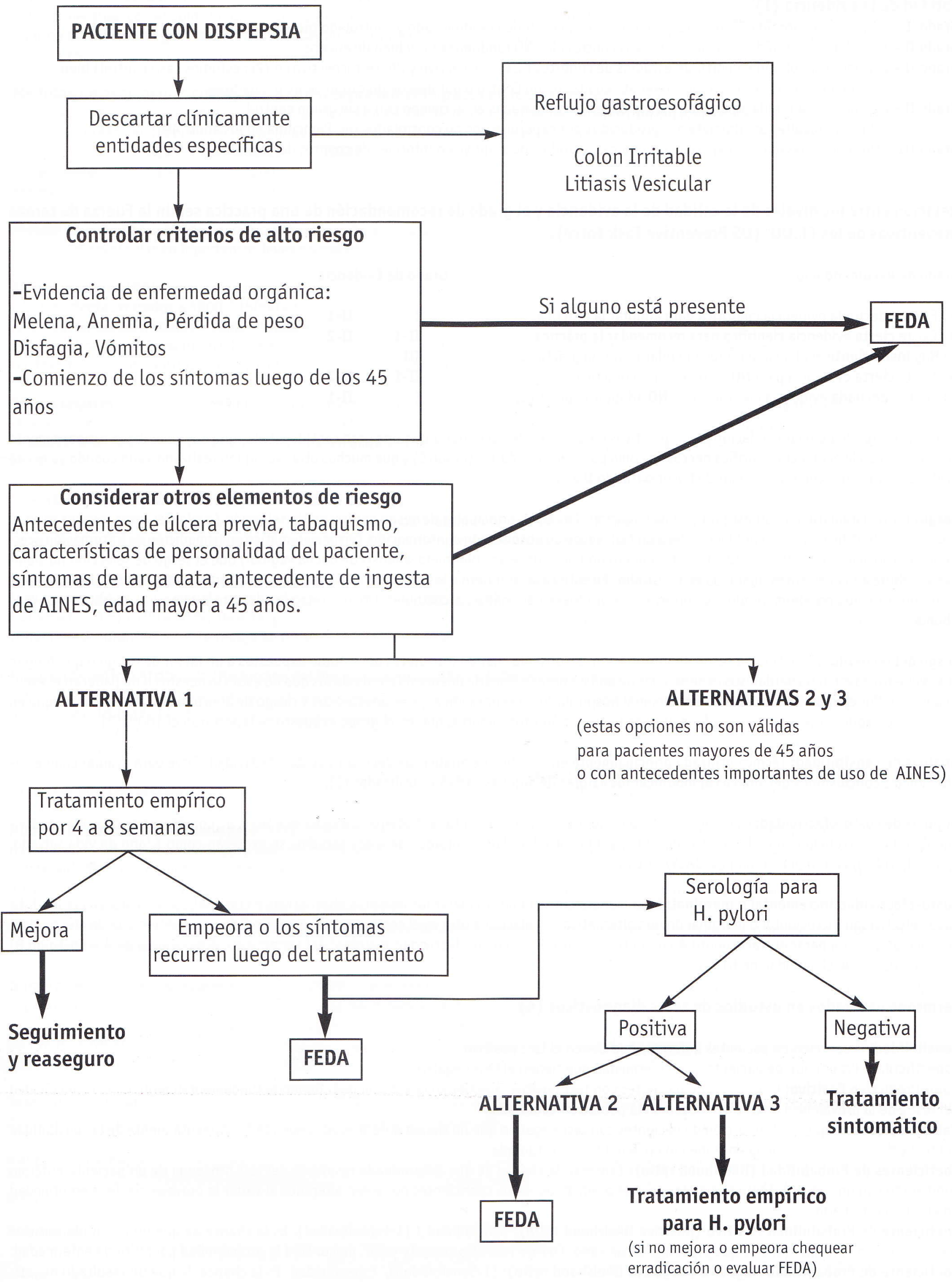

FEDA: Fibro-endoscopía digestiva alta. 